\title{
Comparing the Parameters of Positioning ACTUATORS USED FOR ROBOTS
}

\author{
SEMJON, J.; VARGA, J. \& TUleja, P.
}

Abstract: Positioning actuators equipped precise reducers are used in the construction of facilities that require high resulting accuracy and position repeatability. Parameters positioning actuators deployed in robotic devices excel in for their high accuracy, but also the ability to withstand high overturning moment. The reason for article publication, is the possibility of compare the features of high precision actuators similar parameters of installed various types of reducers. Comparison of catalogue parameters positioning actuators allows you to choose the most suitable actuator for specific applications. Implementation of measurement of the individual characteristics of the actuators is possible to confirm or refute the parameters stated by the manufacturer. In addition, the measurement can be determined by the characteristics of the producers which in their catalogues do not appear. These characteristics may decide about deploying optimal actuator for the application.

Key words: actuator, robot, parameter, precise positioning, methodology
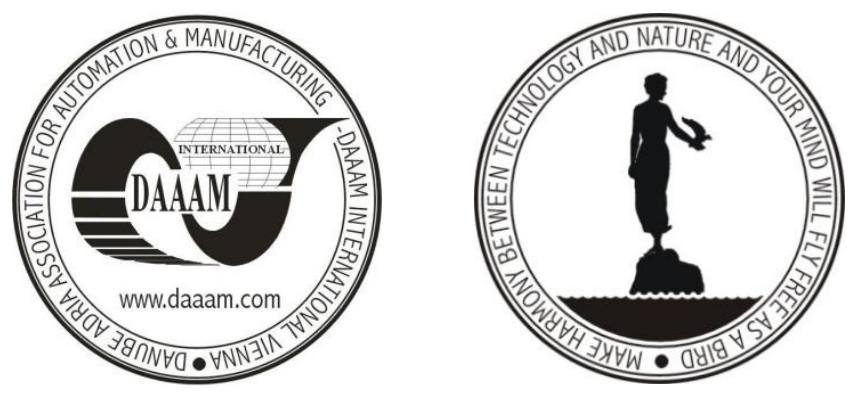

Authors' data: Dipl.-Ing. Semjon, J[an]; Dipl.-Ing. Varga, J[ozef]; Dipl.-Ing. Tuleja, P[eter] Technical University of Kosice, Faculty of Mechanical Engineering Letna 9, 04200, Kosice, Slovakia, jan.semjon@tuke.sk, jozef.varga.2@tuke.sk, peter.tuleja@tuke.sk

This Publication has to be referred as: Semjon, J[an]; Varga, J[ozef] \& Tuleja, P[eter] (2014). Comparing the Parameters of Positioning Actuators Used for Robots, Chapter 50 in DAAAM International Scientific Book 2014, pp.615-624, B. Katalinic (Ed.), Published by DAAAM International, ISBN 978-3-901509-98-8, ISSN 17269687, Vienna, Austria

DOI:10.2507/daaam.scibook.2014.50 
Semjon, J.; Varga, J. \& Tuleja, P.: Comparing the Parameters of Positioning Actuat...

\section{Introduction}

Positioning of actuators deployed in manufacturing machines and robots are one of the important components to ensure an accurate positioning of the executive body. Their deployment is contingent needs of the equipment in which they are installed.

The role of the actuator (drive), see figure 1 for robot (machinery, equipment) is to lead the executive authority in the prescribed manner to the designated state of motion so that the working mechanism to implement the required positioning (handling or technological) operation with specified accuracy and speed. A suitable choice of actuator is depended not only on its mechanical parameters, but also on the way the management and metering. Performance data of actuators from various manufacturers are comparable, the difference between them mostly based on their construction. (Cop \& Durovsky, 2013)

The current trend in the design of new actuators for precision production equipment and robots is to ensure high accuracy resulting in the reduction size and weight of the actuator. This trend can only knowledge be achieved exploitation of mechatronic components focusing to the appropriate cooperation between the servo motor, gear system, sensors and control technology integrated in a compact actuator. Such an actuator should be easy to build into new concepts various devices developed based on light case of composite materials. Methodological validate the parameters of precision actuators has been based on functional and parametric analysis, the general structure of the actuator and its recovery. Analytical evaluation of sequence construction for actuator structure is calculated based on the required parameters and properties of the actuator, and practical testing is best done by comparing selected parameters samples actuators on measurement equipment. (Hajduk et al., 2013); (Vagas et al., 2012)

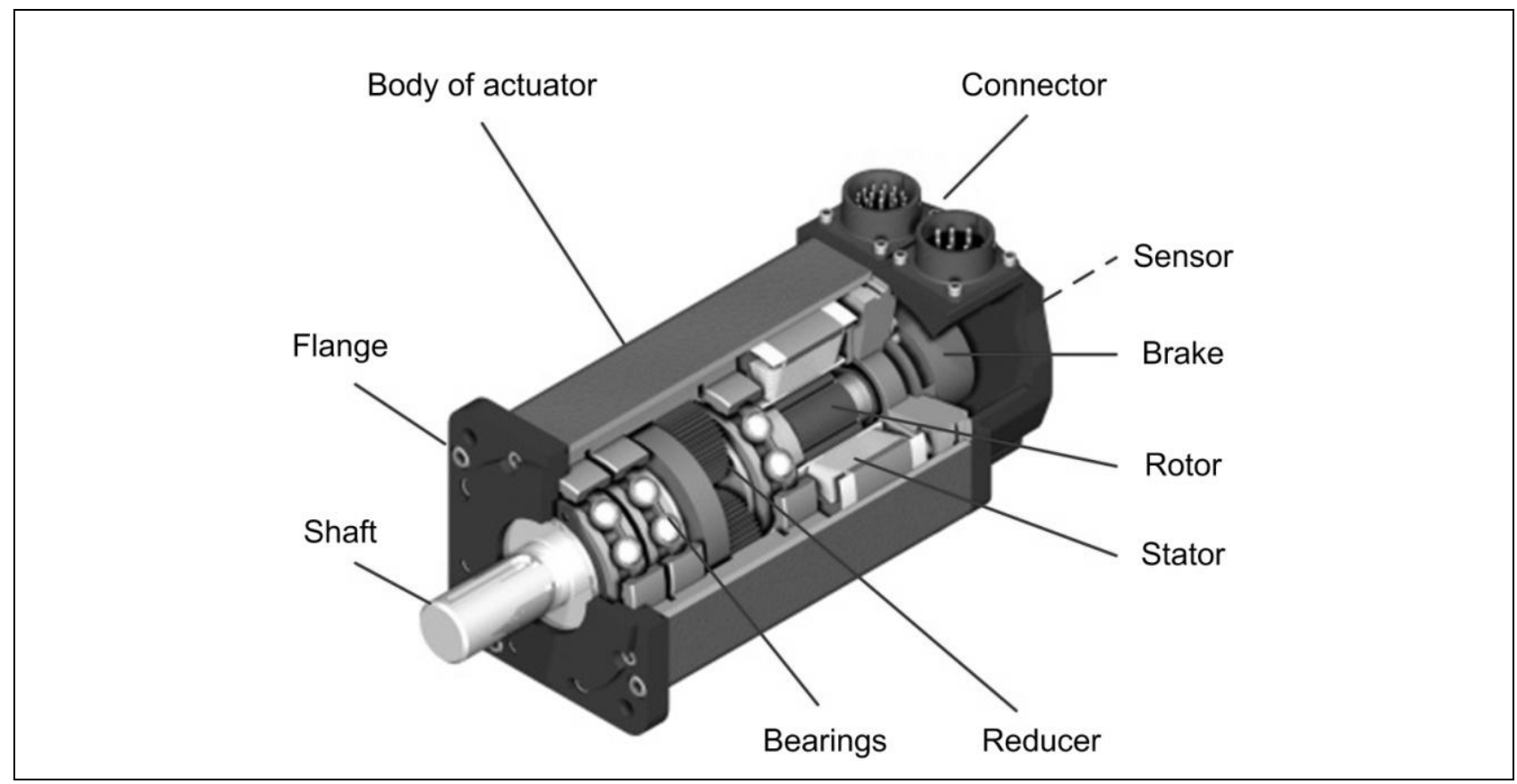

Fig. 1. Actuator SLG (Exlar) 


\section{Basic requirements for positioning actuators in robots}

The objective of drives - actuator robots is to ensure quiet, smooth and nonshock course of or handling or technological activities. Another objective is a high accuracy positioning. For this, given the high inertial forces and speed, is needed low weight and small dimensions. Among the basic requirements drives for robots we include: (Semjon et al., 2013)

- soft start and braking,

- high positioning accuracy,

- sufficient positional stiffness,

- minimum weight,

- minimum dimensions,

- appropriate spatial arrangement.

From the actuators used in robot drives are required by additional requirements:

- high performance per unit weight, good regulatory properties,

- high efficiency, quiet operation and smooth running even at low speeds,

- high durability, minimal environmental impact,

- continuous engine power or performance overload ability,

- range and accuracy position control, speed and torque,

- maintenance, operational reliability, durability and diagnostics,

- economic indicators.

For compare of samples were selected actuators from companies Harmonic Drive, Wittenstein alpha and SPINEA. Size range the actuator represents the value of the permanent static torque output on gearbox 50 to $71.25 \mathrm{Nm}$. Due to the lack of reference to all the data from individual producer's actuators comparison contains only the data that was detectable. By comparing of actuators towards the sample firms SPINEA to determine the basic conditions for the deployment of individual actuators to appropriate installations. (Semjon et al., 2011)

We compared the following sample positioning actuators:

1) Wittenstein alpha, type TPM+ power, No.: TPMP-010S-100K-6KB0-094A-W1

2) Harmonic Drive, type LynxDrive, No.: 20C-160-AO-H-MGH-B

3) SPINEA, type DriveSpin DS70, No.: (DS70-075-4SB076 and DS70-0753SB076)

\section{Comparison of the first pair of actuators TPMP 010 and DS 70}

Figure 2 shows the samples compared actuators. Both actuators are equipped with a built-in temperature sensor and connection to the control system using the interface Hiperfice. Actuators are primarily intended for incorporation into static equipment therefore has a value of $560 \mathrm{~V}$ power. 


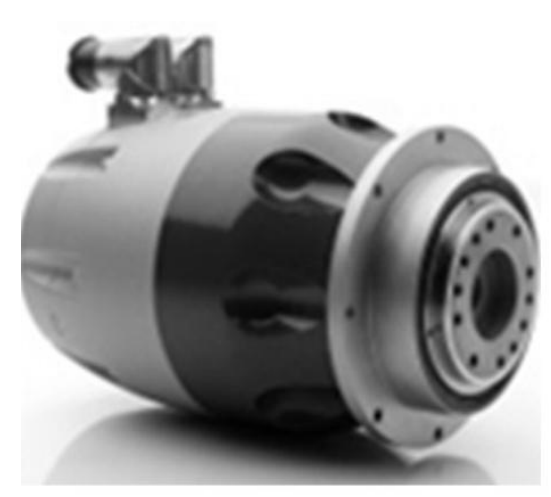

TPMP 010

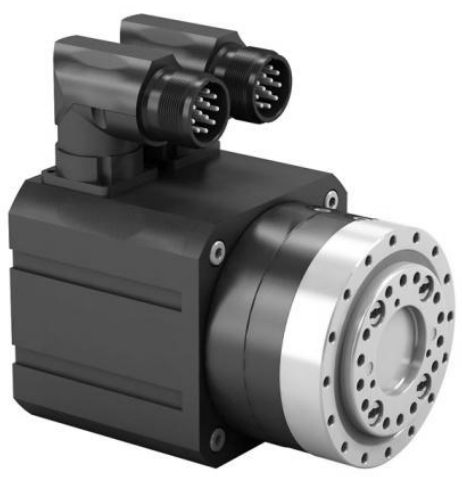

DriveSpin DS70

Fig. 2. Actuators TPMP 010 and DriveSpin DS 70

Technical characteristic of actuators TPMP 010 and DS 70 are shown in Table 1 . The table contains only the selected parameters focusing on the parameters that will be measured on the measuring workplace. (***, 2014b, 2014c).

\begin{tabular}{|c|c|c|c|}
\hline Parameters & Indication & TPMP-010S & $\begin{array}{c}\text { DriveSpin } \\
\text { DS70 } \\
(-075-4 S B 076)\end{array}$ \\
\hline DC Bus voltage [V] & $U_{d c}$ & 560 & 560 \\
\hline Maximum speed at outlet $\left[\mathrm{min}^{-1}\right]$ & $n_{2 \max }$ & 60 & 66.67 \\
\hline Motor rated AC current (A) & IO & 1.9 & 1.18 \\
\hline Motor peak current [A] & $I_{\max }$ & 6 & 4.4 \\
\hline $\begin{array}{l}\text { Maximum permissible acceleration } \\
\text { torque on output gearbox }[\mathrm{Nm}]\end{array}$ & $T_{2 B}$ & 100 & 100 \\
\hline Rated output torque $[\mathrm{Nm}]$ & $T_{20}$ & 60 & 71.25 \\
\hline Max. allowable input speed $\left[\mathrm{min}^{-1}\right]$ & $n_{\max }$ & 6000 & 5000 \\
\hline Acceleration/braking torque $[\mathrm{Nm}]$ & $T_{1 \max }$ & - & 100 \\
\hline Reduction ratio & $i$ & 100 & 75 \\
\hline Protection class & IP & IP65 & IP64 \\
\hline Weight with brake $[\mathrm{kg}]$ & $m$ & 6.0 & $2.35 \div 2.8$ \\
\hline Brake voltage [V] & $U_{\text {brake }}$ & 24 & 24 \\
\hline Tilting stiffness $[\mathrm{Nm} / \mathrm{arcmin}]$ & Mt & - & 35 \\
\hline Tilting moment $[\mathrm{Nm}]$ & $T$ & 270 & 143 \\
\hline
\end{tabular}

Tab. 1. Technical characteristic TPMP 010 and DriveSpine DS70

Producer referred to interdependence of output torque and output speed actuator TPMP 010 and DS 70 is shown in figure 3. Highlighted value indicates the maximum value of output torque in continuous working cycle. 
Evaluation of the comparison:

- The actuators have a different gear ratio, therefore differ somewhat in the course of the mechanical characteristics.

- The maximum torque of the two actuators is the same at nominal moment DS70 has a different course to speed.

- Actuator DS70 reaches the torque at a lower power level, the less current consumption to a third of the weight of TPMP.

- Actuator TPMP has a higher degree of protection against water class as DS70. Both actuators are dustproof (IP 6x), TPMP is resistant to water or jet (IP x5), DS70 only against splashing water (IP x4).
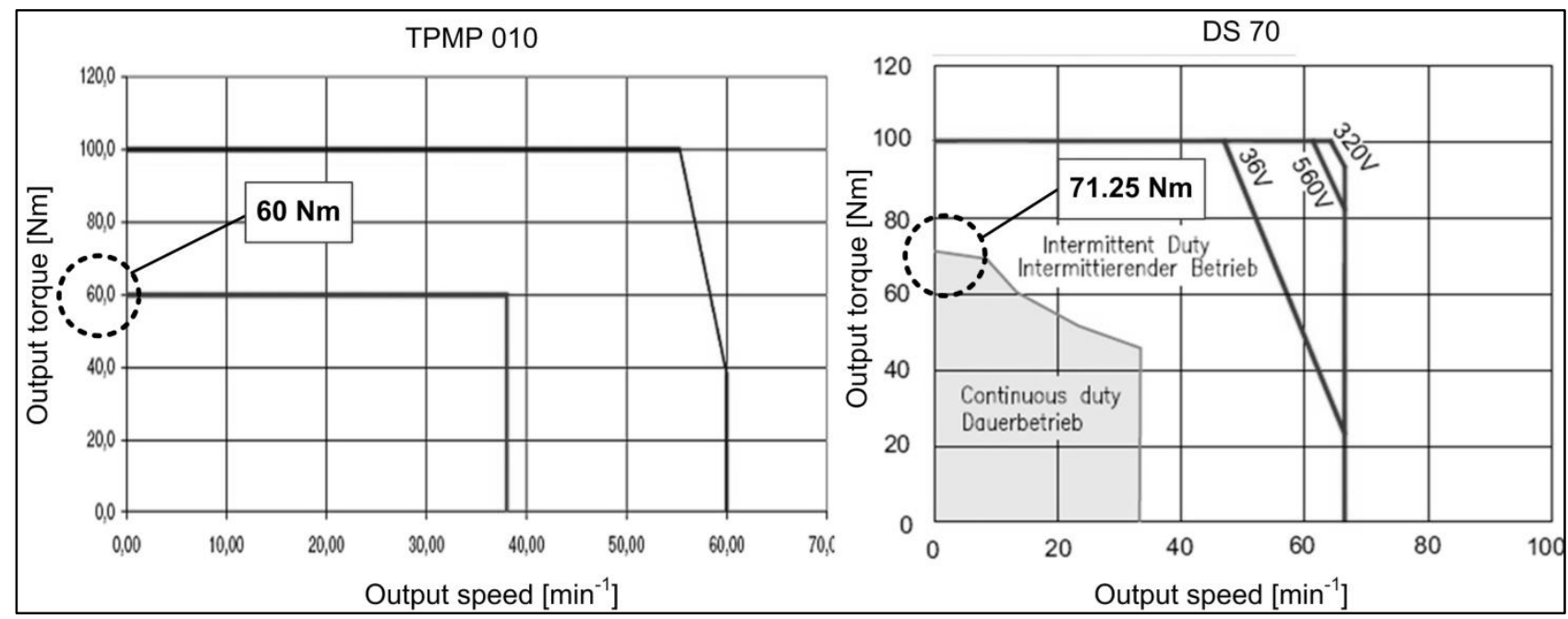

Fig. 3. Catalogue data for output torque and speed TPMP 010 and DS 70

\section{Comparison of the second pair of actuators LynxDrive 20C and DS 70}

Figure 4 shows the samples of compared actuators LynxDrive 20C and DS 70 actuators that are equipped with a built-in temperature sensor and connection to the control system by using the interface Hiperfice. Actuators have a voltage about maximum value of $430 \mathrm{~V}$.

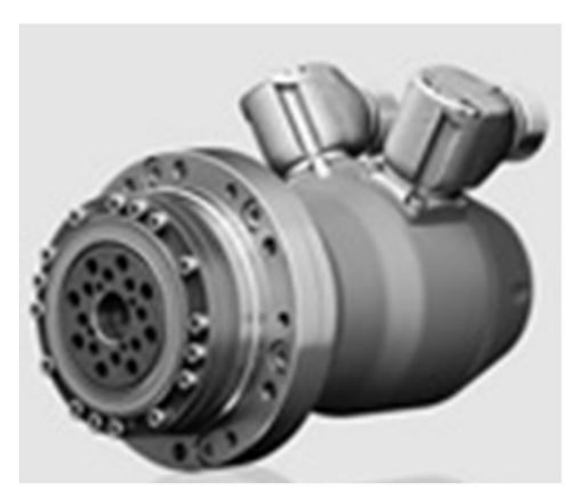

LynxDrive 20C

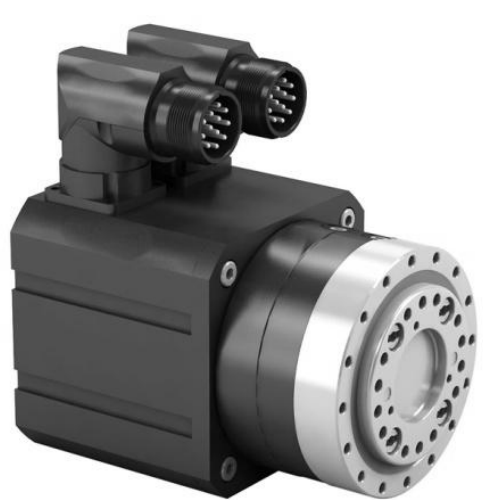

DriveSpin DS70

Fig. 4. Actuators LynxDrive 20C and DriveSpin DS 70 
Semjon, J.; Varga, J. \& Tuleja, P.: Comparing the Parameters of Positioning Actuat...

Technical characteristic of actuators LynxDrive 20C and DriveSpin DS 70 are shown in Table 1. (***, 2014a, 2014b)

\begin{tabular}{|c|c|c|c|}
\hline Parameters & Indication & LynxDrive 20C & $\begin{array}{c}\text { DriveSpin DS70 } \\
(-075-3 S B 076)\end{array}$ \\
\hline DC Bus voltage [V] & $U_{d c}$ & $220-430 \mathrm{~V}$ & 400 \\
\hline Maximum speed at outlet $\left[\mathrm{min}^{-1}\right]$ & $n_{2 \max }$ & 41 & 66.67 \\
\hline Motor rated AC current (A) & I0 & 0,9 & 1.04 \\
\hline Motor peak current $[\mathrm{A}]$ & $I_{\max }$ & 1.6 & 4,4 \\
\hline Rated output torque [Nm] & $T_{20}$ & 50 & 71.25 \\
\hline Motor rated speed $\left[\mathrm{min}^{-1}\right]$ & $n$ & 3500 & 4500 \\
\hline Max. allowable input speed $\left[\mathrm{min}^{-1}\right]$ & $n_{\max }$ & 6500 & 5000 \\
\hline Acceleration/braking torque $[\mathrm{Nm}]$ & $T_{1 \max }$ & 92 & 100 \\
\hline Reduction ratio & $i$ & 160 & 75 \\
\hline Protection class & IP & IP65 & IP64 \\
\hline Weight with brake $[\mathrm{kg}]$ & $m$ & 2.6 & $2.35-2.8$ \\
\hline Brake voltage [V] & $U_{\text {brake }}$ & 24 & 24 \\
\hline Tilting stiffness [Nm/arcmin] & Mt & - & 35 \\
\hline Tilting moment $[\mathrm{Nm}]$ & $T$ & 118 & 143 \\
\hline
\end{tabular}

Tab. 2. Technical characteristic LynxDrive 20C and DriveSpine DS70

Producer referred to interdependence of output torque and output speed actuator LynxDrive 20C and DS 70 is shown in figure 5. Highlighted value indicates the maximum value of output torque in continuous working cycle.

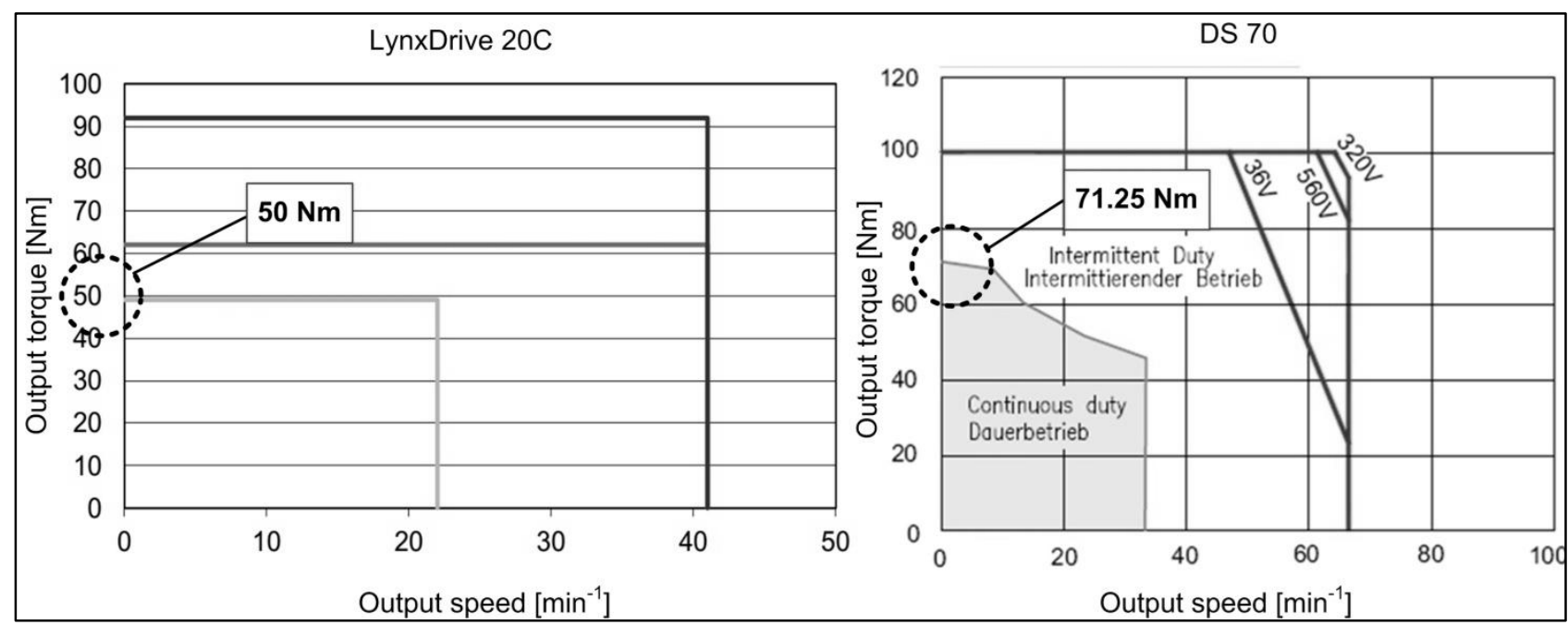

Fig. 5. Catalogue data of output torque and speed LynxDrive 20C and DS 70

Evaluation of the comparison:

- Actuators are significantly different gear ratio, so the differences in mechanical characteristics significantly.

- Other electrical parameters of both actuators are similar, including the total weight. 
- Actuator LynxDrive has a higher degree of protection against water class as DS70. Both actuators are dustproof (IP 6x), LynxDrive is resistant to water or jet (IP x5), DS70 only against splashing water (IP x4).

\section{The results of measurements of positioning actuators on measuring workplace}

Comparison of real characteristics to individual actuators was realized in rehearsal room company SPINEA and to the measuring workplace Technical University of Kosice. On figure 6 is shown the results of measurements of load and deformation acting on the output flange actuators TPMP 010, LynxDrive 20C and DriveSpin DS70. A time measurement on individual actuators is different due to the different sizes of gear ratio of individual actuators.

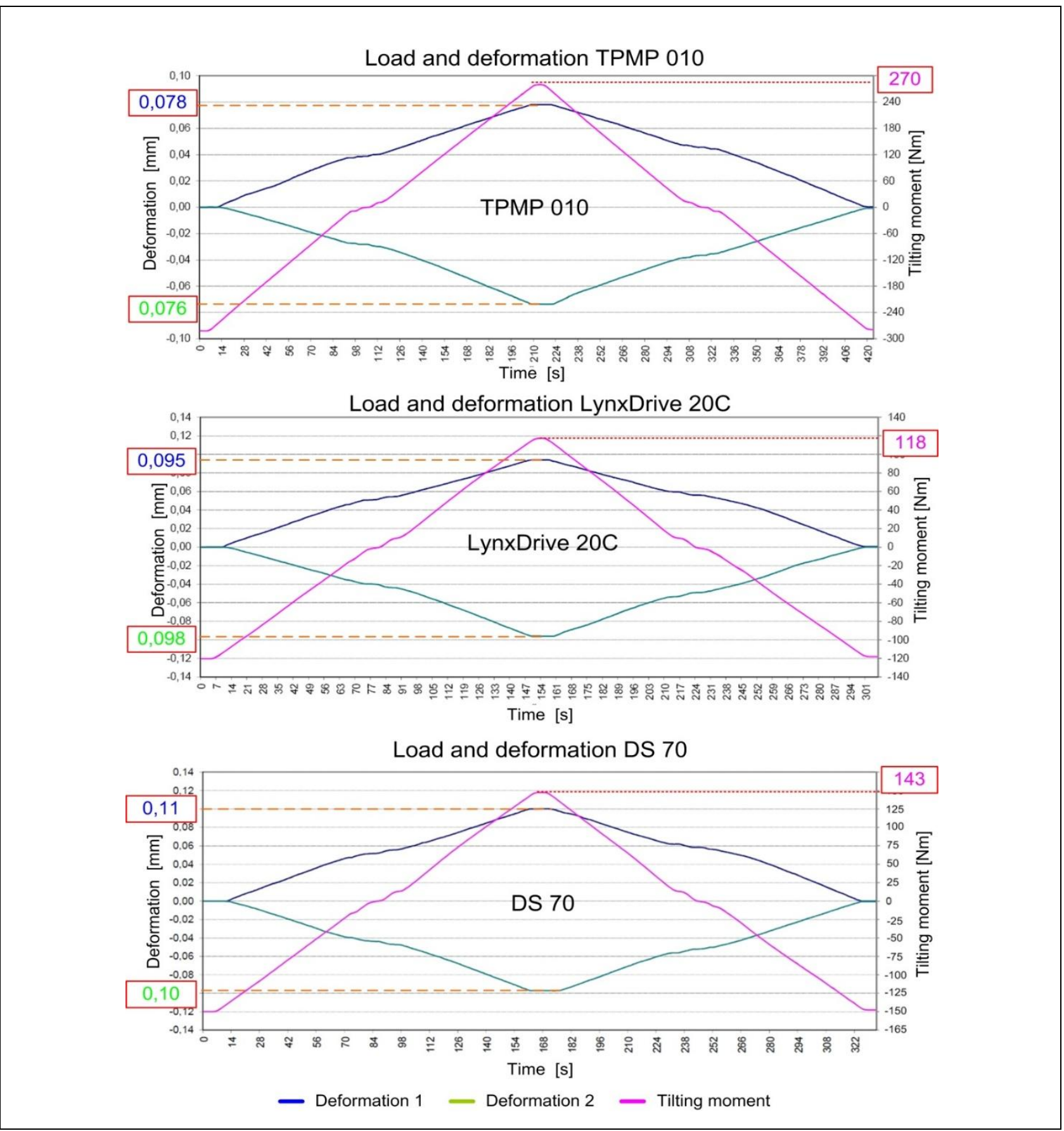

Fig. 6. The results of measurements of load and deformation actuators 
On the measuring workplace was carried out a series of measurements, in which were verified various characteristics. Among the fundamental is the size of load and deformation at the exit of the actuator. Furthermore, size of the overturning tilting moment and tilting stiffness.

7.

Measuring was focused on the fair value of torsional stiffness is shown in figure

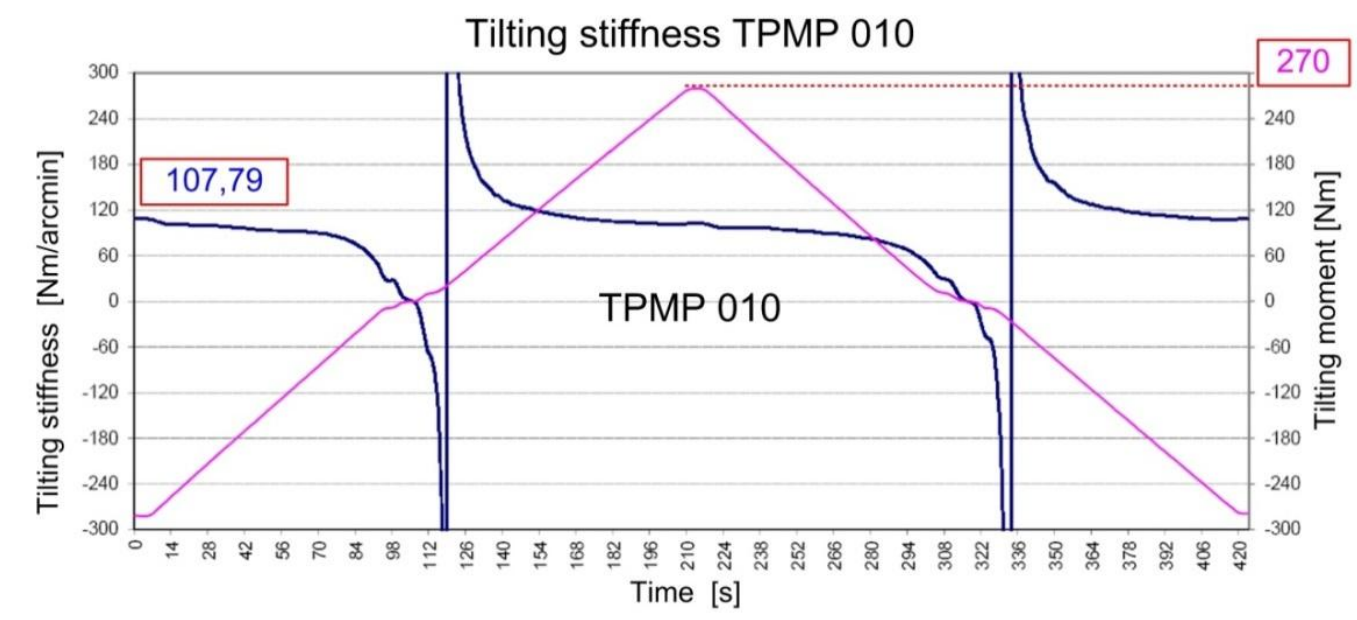

Tilting stiffness LynxDrive 20C

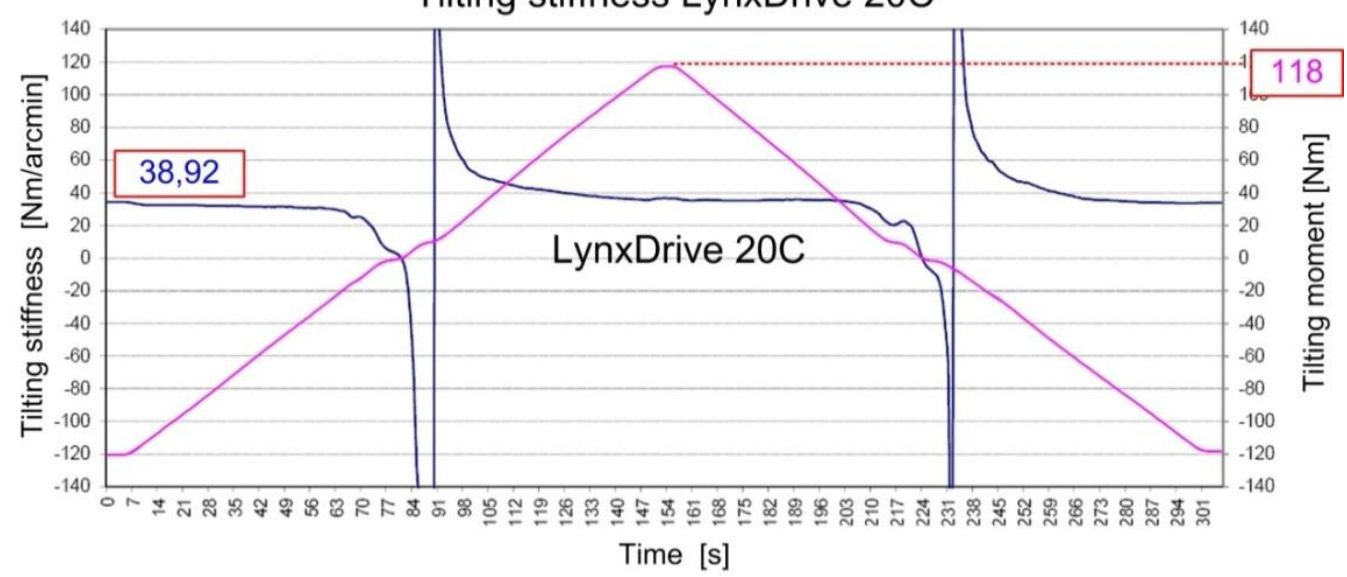

Tilting stiffness DS 70

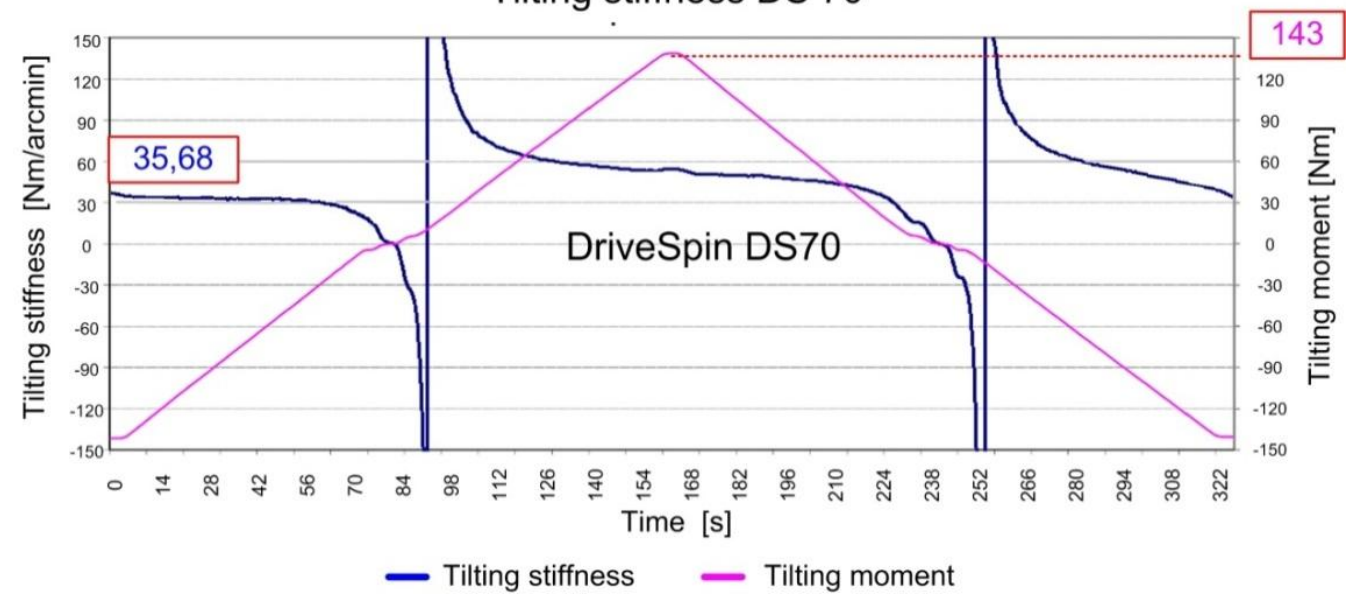

Fig. 7. The results of measurements for tilting stiffness in actuators 
The maximal value of the tilting stiffness in compared achieves is the largest actuator TPMP 010. The measured value of tilting stiffness is ranged from 102.4 to 109.78 Nm/arcmin. In the comparison actuators LynxDrive 20C and DS 70 it can be stated that the resulting tilting stiffness values are about the same. The manufacturer of specified value tilting stiffness actuator DS 70 was by measuring slightly exceeded.

The measurement was realized out at $20-22{ }^{\circ} \mathrm{C}$ in one day. Number of measurements was 3, the paper shows the mean value of the measurements. Measurement was realized on the measuring equipment fitted with appropriate connection flanges. Measurement task is to determining the fair value of the actuator at maximum load. At the output flange of the actuator was placed burden, the size of which corresponds to the maximum permissible load actuator. The burden is on the sliding arm, in order to simulate the load and the value of 50 and $100 \%$. Rotation arm of the burden towards the basic position has been implemented in four basic positions $\left(0,90,180\right.$ and $\left.270^{\circ}\right)$.

By measuring the individual positioning actuators following results were obtained:

- TPMP 010 - The maximum tilting moment value is $270 \mathrm{Nm}$, the value of deformation are in the range of 0.076 to $0.078 \mathrm{~mm}$. For half the value of the tilting moment $135 \mathrm{Nm}$ is value of deformation in the range of 0.044 to 0.045 mm.

- LynxDrive 20C - The maximum tilting moment value is $118 \mathrm{Nm}$, the value of deformation are in the range of 0.095 to $0.098 \mathrm{~mm}$. For half the value of the tilting moment $59 \mathrm{Nm}$ is value of deformation in the range of 0.059 to 0.060 $\mathrm{mm}$.

- DriveSpin DS70 - The maximum tilting moment value is $143 \mathrm{Nm}$, the value of deformation are in the range of 0.10 to $0.11 \mathrm{~mm}$. For half the value of the tilting moment $71.5 \mathrm{Nm}$ is value of deformation in the range of 0.058 to $0.059 \mathrm{~mm}$.

Measurement of said actuators is confirmed that the on the size of deformation output flange of the actuators has an impact the construction design of the actuator. Within the framework the design of the main positioning actuator decides gear principle. The actuator TPMP 010 is used gearbox using the planetary principle. Therefore, this actuator has the largest structural dimensions of the largest value and of the tilting moment. In the case of actuator LynxDrive 20C is used harmonic reducer, which the relatively small dimensions of well construction resists incurred by deformation. Actuator DS 70 is mounted cycloidal reducer, which reaches the small dimensions of the highest values of output torque, but due to the large number of components is the value of deformation at maximum tilting moment the average.

\section{Conclusion}

Based on realized measurements it can be stated that the manufacturers actuators meet the declared characteristics. A during implemented the measurements were found exceedances at some characteristics of a maximum of $3 \%$, which is attributable 
to the tolerance field of the measuring system. The best value of the overturning moment reaches actuator TPMP010, but has a high weight and overall dimensions, which increases the demand for constructing a robotic arm. Therefore, for the proposed application - a robotic arm as the best alternative in terms of the ratio of torque, the heeling moment, dimensions and total weight actuator DriveSpin DS70075. Its biggest advantage is the relatively low weight at high rated output torque.

Precision actuators deployed in production and robotic equipment must meet the requirements of the device in which they are used. Each actuator consists of several components made in a certain tolerance field, and their mutual connection arise the actuator from specific characteristics of accuracy and position repeatability. Their resulting accuracy the way for managing a mutual communication is essential for proper and long-term functioning facilities. Validate the parameters and a property of precise positioning actuators is based on the need for accurate quantification of their real characteristic.

Deployment of precise positioning actuator in machinery tends to increase. It will therefore be necessary to continue their verification options, increasing their intelligence and ensure their easier connection to the machine and robotic systems.

\section{Acknowledgements}

This contribution is the result of the project implementation: Research modules for intelligent robotic systems (ITMS: 26220220141) supported by the Research \& Development operational Program funded by the ERDF.

\section{References}

Cop, V. \& Durovsky, F. (2013). Advanced mechatronic components, driving and positioning modules for intelligent manufacturing and robotics systems, Internationales Forum Mechatronik, pp. 2-19, ISBN 978-3-033-04189-9, Switzerland, 10/2013, ZHAW - Institute of Mechatronic Systems, Winterthur.7

Hajduk, M. et al. (2013). Trends in industrial robotics development, In. Applied Mechanics and Materials, Vol. 282 (2013), pp. 1-6, ISSN 1660-9336

*** (2014a) http://www.harmonicdrive.de/ produkte/index.php/ servoprodukte/ antriebe-ohne-hohlwelle/lynxdrive.html Accessed: 2014-06-03

*** (2014b) http://www.spinea.sk/public/media/0435/DriveSpin_catalogue_2012.pdf Accessed: 2014-06-02

*** (2014c) http://www.wittenstein-alpha.de/en/mechatronic-system-solutions.html Accessed: 2014-06-04

Semjon, J. et al. (2011). Benchmarking analysis of the application of small bearing reducers and actuators in service robotics, In: Fascicle of Management and Technological Engineering, pp. 5.303-5.306, ISBN 1583-0691, Romania, 5/2011, University of Oradea, Oradea

Semjon, J. et al. (2013). Procedure selection bearing reducer twinspin for robotic arm, In. Applied Mechanics and Materials, Vol. 245 (2013), pp. 261-266, ISSN 1660-9336 Vagas, M. et al. (2012). The view to the current state of robotics, In. Advanced Materials Research, Vol. 463-464 (2012), pp. 1711-1714, ISSN 1022-6680 